\title{
Collusion under Imperfect Monitoring with Asymmetric
}

\section{Firms*}

\author{
Luke Garrod $^{\dagger}$ and Matthew Olczak ${ }^{\ddagger}$
}

October 16, 2017

\begin{abstract}
We explore the effects of asymmetries in capacity constraints on collusion where market demand is uncertain and where firms must monitor the agreement through their privately observed sales and prices. In this private monitoring setting, we show that all firms can infer when at least one firm's sales are below some firm-specific "trigger level". This public information ensures that firms can detect deviations perfectly if fluctuations in market demand are sufficiently small. Otherwise, there can be collusion under imperfect public monitoring where punishment phases occur on the equilibrium path. We find that symmetry facilitates collusion. Yet, we also show that if the fluctuations in market demand are sufficiently large, then the optimal collusive prices of symmetric capacity distributions are actually lower on average than the competitive prices of asymmetric capacity distributions. We draw conclusions for merger policy.
\end{abstract}

JEL classification: D43, D82, K21, L12, L41

Key words: capacity constraints, mergers, collusion, imperfect monitoring

\footnotetext{
*This paper builds on Centre for Competition Policy Working Paper 10-3. We are grateful for comments from Steve Davies, Joe Harrington, Morten Hviid, Patrick Legros, Bruce Lyons, Volker Nocke, Peter Ormosi, Chris M. Wilson, and two anonymous referees. We have also benefited from the comments of seminar participants at the ESRC Centre for Competition Policy, the International Industrial Organization Conference (IIOC) 2014, the Competition and Regulation European Summer School (CRESSE) conference 2014, the European Association of Research in Industrial Economics (EARIE) conference 2014, and the Bergen Center for Competition Law and Economics (BECCLE) conference 2015. The usual disclaimer applies.

${ }^{\dagger}$ School of Business and Economics, Loughborough University, LE11 3TU, UK, email: l.garrod@lboro.ac.uk

¥Aston Business School, Aston University, Birmingham, B4 7ET, UK, email: m.olczak@aston.ac.uk
} 


\section{Introduction}

The recent collusion theory literature has developed a clear consensus that asymmetries hinder collusion. For example, this result is robust to whether asymmetries are in terms of firms' capacity constraints (see Compte et al., 2002; Vasconcelos, 2005; and Bos and Harrington, 2010 and 2015) or the number of differentiated products that each firm sells (see Kühn, 2004). These papers in particular have been important for merger policy as they have highlighted which types of mergers can cause coordinated effects, that is, an increased likelihood of tacit collusion postmerger. More specifically, with respect to capacity constraints, Compte et al. (2002) show that collusion can be more difficult as the capacity of the largest firm is increased through a merger, and Vasconcelos (2005) finds that collusion is hindered when the largest firm is larger or when the smallest firm is smaller. Bos and Harrington (2010) show that increasing the capacity of medium-sized firms can facilitate collusion, if only a subset of firms in the market are involved in the collusion. ${ }^{1}$

In practice, the degree to which firms can monitor each other's actions plays an important part in determining whether a merger causes coordinated effects. Yet, all of the papers above assume there is perfect observability of rivals' actions, so deviations from the collusive strategies will be detected immediately. In contrast, many mergers occur in markets in which there is the potential for secret price cuts. This may be the case, for example, in upstream businessto-business markets where transaction prices can be unrelated to posted prices. Consequently, it is inappropriate to consider the effects of such mergers in terms of collusion under perfect observability. Instead, they should be considered in the context of imperfect monitoring, where firms are uncertain over whether their rivals have followed their collusive strategies or not (see Green and Porter, 1984; and Harrington and Skrzypacz, 2007 and 2011). However, while the models in this literature provide many interesting insights into the sustainability of collusion, it is difficult to draw implications for merger policy from them, because they analyse collusion with symmetric firms.

In this paper, we begin to fill this gap in the literature by exploring the effects of asymmetries in capacity constraints on collusion under imperfect monitoring. We achieve this by extending Compte et al. (2002) to a setting where there is demand uncertainty and where firms never directly observe their rivals' prices or sales. Thus, similar to the imperfect monitoring setting

\footnotetext{
${ }^{1}$ Fonseca and Normann (2008) also find that asymmetries in capacity constraints hinder collusion in laboratory experiments.
} 
first discussed by Stigler (1964), each firm must monitor the collusive agreement using their own privately observed sales. In this regard, our model is related to Tirole's (1988, p.262-264) model of private monitoring that captures the results of Green and Porter (1984) in a Bertrand framework (see also Amelio and Biancini, 2010). Yet, unlike Tirole (1988), where there is a chance in each period that market demand will be zero, in our model market demand is drawn from an interval, where all possible states of demand are positive. We use this model to investigate whether collusion is facilitated or hindered as capacity is reallocated among the firms to draw implications for merger policy.

Using information from their privately observed sales, we show that all firms can always infer when at least one firm's sales are below some firm-specific "trigger level". The optimal trigger level for each firm is determined by the largest possible sales consistent with them or a rival being undercut on price. Thus, if all firms set a common price, then all firms' sales will exceed their respective trigger levels when the realisation of market demand is high, otherwise they can all fall below the trigger levels. Yet, if all firms do not set a common price, then the highest-priced firms will receive sales below their trigger levels and the lower-priced firm(s) can infer this. ${ }^{2}$ Consequently, we restrict attention to equilibria in public strategies, known as perfect public equilibria, where firms condition their play upon this public information (i.e. whether all firms' sales are greater than their trigger levels or not). We show that if fluctuations in market demand are small, then such strategies ensure monitoring is perfect, because firms will only ever receive sales below their trigger levels if they are undercut. However, if fluctuations in market demand are large, then collusive sales will also fall below the trigger levels when the realisation of market demand is low. This implies, in contrast to Compte et al. (2002), that there is uncertainty as to whether rivals have followed the collusive strategies or not, so punishment phases must occur on the equilibrium path to provide firms with the correct incentives to collude.

We solve for an optimal perfect public equilibrium. ${ }^{3}$ We find that asymmetries hinder collusion whether monitoring is perfect or imperfect. For instance, the critical discount factor is

\footnotetext{
${ }^{2}$ Note that this information is common knowledge in our framework, because a deviation by a firm affects the sales of all of its rivals. In contrast, this information may not be common knowledge in a framework where firms' products are spatially differentiated, as in the Salop circle, for example, because then firms located next to a deviator would experience lower sales but other firms may not.

${ }^{3}$ In the main paper, we use a simple strategy profile, similar to Tirole (1988), where firms revert to the static Nash equilibrium for a number of periods when they receive a bad signal. In an online appendix, we use the techniques of Abreu et al. $(1986,1990)$ to show that this simple approach generates the maximal equilibrium profits.
} 
higher when the largest firm is larger and it can be higher when the smallest firm is smaller. The reason for the former is that the punishment is weaker when the largest firm has more capacity. The latter is due to the fact that deviations by the smallest firm are most difficult for rivals to detect, because each rival's resultant sales are most similar to its collusive sales. Thus, decreasing the size of the smallest firm can make monitoring more difficult. Another implication of this is that punishment phases occur more often on the equilibrium path when the smallest firm has less capacity, and the optimal equilibrium profits are lower as a result. The size of the other firms' capacities do not affect the the equilibrium profits or the critical discount factor.

After solving the model, we then use it to draw implications for merger policy. In particular, we analyse both the coordinated and unilateral effects of mergers in a unified framework. Unilateral effects arise if a firm has an individual incentive to raise prices post-merger. It is well understood that unilateral effects are associated with asymmetric post-merger market structures and coordinated effects are associated with symmetric post-merger market structures (see Ivaldi et al., 2003a and 2003b). As discussed by Kühn (2001) and Motta et al. (2003), this implies that there is a tradeoff between such effects when the degree of asymmetry in a market is altered by a merger or divestiture remedy: increasing asymmetries reduces the likelihood of coordinated effects but raises the likelihood of unilateral effects, and vice versa. However, in the previous theoretical literature, these effects have been modelled independently of each other. For example, in the framework of Compte et al. (2002), either the monopoly price is sustainable in every period, in which case only coordinated effects matter, or collusion is never sustainable at any price, so only unilateral effects matter. Consequently, their focus is solely on the coordinated effects of mergers on the critical discount factor. In contrast, our model allows for a more continuous treatment of unilateral and coordinated effects, because play can alternate between phases of collusion and competition on the equilibrium path. As a result, our model is ideal to analyse the tradeoff between coordinated and unilateral effects.

In the framework of Compte et al. (2002), a merger that causes coordinated effects is more harmful to consumer welfare than compared with an alternative that causes unilateral effects. The reason is that firms will optimally share the monopoly profits in every future period if collusion is sustainable, so only a merger to monopoly would be equally as bad in terms of unilateral effects. A similar point is made more generally by Röller and Mano (2006). They argue that a merger that disrupts pre-merger collusion, by enhancing the market power of a single firm, should be pro-competitive because "it is preferable that any coordination is by only a subset of firms (i.e. the merging parties) rather than all firms (tacitly)" (p.22). However, in contrast to this, 
we show that unilateral effects can be more harmful than coordinated effects. This is due to the fact that firms are not able to share the monopoly profits under imperfect monitoring, because punishment phases occur on the equilibrium path. Consequently, a merger that facilitates collusion by distributing capacity symmetrically can be less harmful to consumer welfare than one that creates a near monopoly. ${ }^{4}$ We demonstrate that if the fluctuations in market demand are sufficiently large, then the optimal collusive prices of symmetric capacity distributions are lower on average than the competitive prices of asymmetric capacity distributions. An implication of this is that it can be appropriate to remedy a merger that causes unilateral effects by imposing a divestment that creates a symmetric market structure, even if this facilitates collusion under imperfect monitoring.

Finally, our model is distinct from the previous literature that analyses collusion with capacity constraints and fluctuations in market demand. The main difference is that our focus is on mergers, which necessarily requires us to model asymmetries in markets with more than two firms. In contrast, the focus of this other literature is on pricing over the business cycle. For instance, Staiger and Wolak (1992) and Knittel and Lepore (2010) endogenise the choice of capacities in an infinitely repeated game. Despite analysing asymmetric games following the capacity choice stage, they restrict attention to duopoly. Other differences are that there is perfect observability and market demand is known when prices are set. In a similar setting to that just described, Fabra (2006) analyses collusion where firms' capacity constraints are exogenous but symmetric.

The rest of the paper is organised as follows. Section 2 sets out the assumptions of the model and solves for the static Nash equilibrium. In section 3, we analyse the repeated game. We first show that there is some public information that firms can condition their play on, and find when monitoring is perfect or imperfect. Then we solve the repeated game and analyse the successfulness of collusion for different capacity distributions. In section 4 , we consider the implications for merger policy, and section 5 concludes. All proofs are relegated to appendix A. In an online appendix, we use the techniques of Abreu et al. $(1986,1990)$ to show that the simple approach used to solve the repeated game in the main text is optimal, in that it generates the maximal equilibrium profits. We also explore the robustness of our results to two key assumptions.

\footnotetext{
${ }^{4}$ This argument is likely to extend to other models where collusion among asymmetric firms is imperfect.
} 


\section{The Model}

\subsection{Basic assumptions}

Consider a market in which a fixed number of $n \geq 2$ capacity-constrained firms compete on price to supply a homogeneous product over an infinite number of periods. Firms' costs are normalised to zero and they have a common discount factor, $\delta \in(0,1)$. In any period $t$, firms set prices simultaneously where $\mathbf{p}_{t}=\left\{p_{i t}, \mathbf{p}_{-i t}\right\}$ is the vector of prices set in period $t, p_{i t}$ is the price of firm $i=\{1, \ldots, n\}$ and $\mathbf{p}_{-i t}$ is the vector of prices of all of firm $i$ 's rivals. Market demand consists of a mass of $m_{t}$ (infinitesimally small) buyers, each of whom are willing to buy one unit provided the price does not exceed their reservation price, which we normalise to 1 . We assume that firms do not observe $m_{\tau}$, for all $\tau \in\{0, \ldots, t\}$, but they know that $m_{t}$ is independently drawn from a continuous distribution $G(m)$, with mean $\widehat{m}$ and density $g(m)>0$ on the interval $[\underline{m}, \bar{m}]$.

Buyers are informed of prices, so they will want to buy from the cheapest firm. However, the maximum that firm $i$ can supply in any period is $k_{i}$, where we let $k_{n} \geq k_{n-1} \geq \ldots \geq k_{1}>0$, without loss of generality. We denote total capacity as $K \equiv \sum_{i} k_{i}$ and the maximum that firm $i$ 's rivals can supply in each period as $K_{-i} \equiv \sum_{j \neq i} k_{j}$. In contrast to the buyers, firm $i$ never observes firm $j$ 's prices, $p_{j \tau}$, or sales, $s_{j \tau}, j \neq i$, for all $\tau \in\{0, \ldots, t\}$. Thus, similar to Tirole (1988), our setting has the feature that all buyers are fully aware of prices, yet all firms are only aware of their own prices. Such a setting is consistent with a market in which all buyers are willing to check the prices of every firm in each period to find discounts from posted prices, but actual transaction prices are never public information. ${ }^{5}$

\subsection{Demand allocation and sales}

Following the literature (for example, see Vasconcelos, 2005; and Bos and Harrington, 2010 and 2015), we make the common assumption that demand is allocated by the following rule:

\section{The proportional allocation rule}

Unsupplied buyers want to buy from the firm(s) with the lowest price among those with spare capacity.

- If the joint capacity of such firms is insufficient to supply all of the unsupplied buyers, then such capacity is exhausted, and the remaining unsupplied buyers now want to purchase

\footnotetext{
${ }^{5}$ In contrast to Tirole (1988), our main results hold when enough buyers are informed of prices, if capacity constraints are binding.
} 
from the firm(s) with the next lowest price among those with spare capacity, and so on. ${ }^{6}$

- If the joint capacity of such firms suffices to supply all of the unsupplied buyers, then each firm supplies an amount of buyers equal to its proportion of the joint capacity.

This allocation rule is commonly considered in the literature in terms of a cartel selecting how much of the market demand each member supplies. Indeed, there are a number of cartels that have allocated demand in proportion to each member's capacity (see the examples in Vasconcelos, 2005, and Bos and Harrington, 2010). However, this seems inappropriate in our model, because members of such cartels are likely to have some knowledge of market demand and rivals' sales when allocating demand, which is not present in our setup. Instead, we have tacit collusion in mind where firms play no role in the allocation of the market demand, other than through the prices they set. Thus, in our framework it seems more appropriate to consider the demand allocation in terms of buyers allocating themselves to firms according to the proportional allocation rule. While it is possible to conceive of ways in which buyers would allocate themselves in this manner in certain settings, the main purpose of this assumption is to develop the simplest conceivable model to compare collusive and non-collusive merger outcomes. However, it should be noted that the allocation rule is not important for the characterisation of the static Nash equilibrium. It is also not important for the (qualitative) analysis of the collusive equilibria in section 3.1 and 3.2. Further discussion is provided in the online appendix, where we consider how the allocation rule can affect the comparative statics analysis in section 3.3.

We also place the following plausible yet potentially restrictive assumption on the capacity distribution:

Assumption 1. $\underline{m} \geq K_{-1}$.

This says that the joint capacity of the smallest firm's rivals should not exceed the minimum market demand, and it ensures that firm $i$ 's sales in period $t$ are strictly positive, for all $i$ and all $m_{t}>\underline{m}$, even if it is the highest-priced firm. The main purpose of this assumption is that it greatly simplifies the characterisation of the static Nash equilibrium when there are more than two asymmetric firms. ${ }^{7}$ It is a sufficient (but not necessary) condition for the static

\footnotetext{
${ }^{6}$ Note that we do not need to specify which buyers are supplied, since all consumers have the same reservation price. In contrast, when consumers' reservation prices differ, the identities of the buyers who are supplied by the firm has important implications for welfare (see for example Vives, 1999, p.124-6).

${ }^{7}$ For more details, see Hirata (2009) who characterises the mixed strategy Nash equilibrium in a static setting with three asymmetrically-capacity constrained firms but without demand uncertainty.
} 
Nash equilibrium profits to be strictly increasing in the capacity of the largest firm, $k_{n}$, and as we demonstrate in the online appendix, it is still possible to characterise the optimal collusive scheme when this assumption is relaxed. To understand the generality of Assumption 1, note that it is not restrictive if all firms can only ever collectively supply as much as the minimum market demand, $\underline{m} \geq K$. Otherwise, for a given level of $\underline{m}$, there is a restriction on the size of the smallest firm in that it cannot be too small. Given the smallest firm's capacity can be no larger than for a symmetric duopoly, a necessary condition for Assumption 1 to hold is that the minimum market demand must be greater than $50 \%$ of the total capacity, $\underline{m} \geq 0.5 \mathrm{~K}$. We also argue in section 4 that Assumption 1 is not very restrictive in the context of mergers. No restriction is placed on the level of the maximum market demand, $\bar{m}$.

Assumption 1 and the proportional allocation rule together imply that firm $i$ 's sales in period $t, s_{i t}\left(p_{i t}, \mathbf{p}_{-i t} ; m_{t}\right)$, for any $p_{i t} \leq 1$, are given by $(1)$, where $\Omega\left(p_{i t}\right)$ denotes the set of firms that price strictly below $p_{i t}$ and $p_{t}^{\max } \equiv \max \left\{\mathbf{p}_{t}\right\}$.

$$
s_{i t}\left(p_{i t}, \mathbf{p}_{-i t} ; m_{t}\right)= \begin{cases}k_{i} & \text { if } p_{i t}<p_{t}^{\max } \\ \min \left\{\frac{k_{i}}{K-\sum_{j \in \Omega\left(p_{i t}\right)} k_{j}}\left(m_{t}-\sum_{j \in \Omega\left(p_{i t}\right)} k_{j}\right), k_{i}\right\} \geq 0 & \text { if } p_{i t}=p_{t}^{\max }\end{cases}
$$

This says that a firm will supply its proportion of the residual demand if it is the highest-priced firm in the market and if capacity is not exhausted, otherwise it will supply its full capacity. This implies that firm $i$ 's expected per-period profit is $\pi_{i t}\left(p_{i t}, \mathbf{p}_{-i t}\right)=p_{i t} \int_{\underline{m}}^{\bar{m}} s_{i t}\left(p_{i t}, \mathbf{p}_{-i t} ; m\right) g(m) d m$, where we drop time subscripts if there is no ambiguity. Furthermore, we write $\pi_{i}(p)$ if $p_{j}=p \leq 1$ for all $j$, such that:

$$
\pi_{i}(p)= \begin{cases}p k_{i} & \text { if } \quad K \leq \underline{m} \\ p k_{i}\left(\int_{\underline{m}}^{K} \frac{m}{K} g(m) d m+\int_{K}^{\bar{m}} g(m) d m\right) & \text { if } \quad \underline{m}<K<\bar{m} \\ p k_{i} \frac{\widehat{m}}{K} & \text { if } \quad \bar{m} \leq K,\end{cases}
$$

for all $i$. So, such profits are maximised for $p^{m} \equiv 1$.

Finally, an important implication of our assumptions is that a firm will meet all demand up to its capacity in any given period. This implies that a deviant is not able to attempt to hide its deviation by limiting the units available at the deviation price. Consequently, our analysis is likely to be appropriate for markets where collusive prices are set at the senior management level, but the total output of the firm is determined at a lower level by sales representatives who are unaware of the collusion. This was the case in many, if not most, detected cartels (see Harrington, 2006, for evidence from Europe). Nevertheless, we have explored this issue 
beyond the analysis presented below and can show that our main results are robust to this alternative setting if deviants are only able to limit their sales below demand to some extent and if this is more difficult for large firms than smaller firms. This may be the case, for example, if the senior managers of a deviant firm can only imperfectly limit the total output of their sales representatives, who are unaware of the collusion, and larger firms have more sales representatives which makes this task more problematic. ${ }^{8}$

\subsection{Static Nash equilibrium}

In this subsection, we analyse the stage game. Consistent with the standard Bertrand-Edgeworth setting, the static Nash equilibrium can be in pure strategies or mixed strategies. While the proof of the former is trivial, we extend the equilibrium analysis in Fonseca and Normann (2008) to our setting of demand uncertainty to solve for the latter. This is also equivalent to the equilibrium analysis of Gal-Or (1984) if firms are symmetric.

Lemma 1. For any given $n \geq 2$ and $K_{-1} \leq \underline{m}$ :

i) if $\underline{m} \geq K$, then there exists a unique pure strategy Nash equilibrium, with profits $\pi_{i}^{N}=k_{i} \forall i$;

ii) if $\underline{m}<K$, then there exists a mixed strategy Nash equilibrium, with profits, $\forall i$ :

$$
\pi_{i}^{N}\left(k_{n}\right)= \begin{cases}\frac{k_{i}}{k_{n}}\left(\int_{\underline{m}}^{K}\left(m-K_{-n}\right) g(m) d m+k_{n} \int_{K}^{\bar{m}} g(m) d m\right) & \text { if } K<\bar{m} \\ \frac{k_{i}}{k_{n}}\left(\widehat{m}-K_{-n}\right) & \text { if } \bar{m} \leq K .\end{cases}
$$

Competition is not effective if the minimum market demand is above total capacity, $\underline{m} \geq K$, so firms set $p_{i}=1$ in equilibrium and receive $\pi_{i}^{N}=k_{i}$ for all $i$. In contrast, if market demand can be below total capacity, firms are not guaranteed to supply their full capacity for every level of demand, so they have incentives to undercut each other. However, by charging $p_{i}=1$, firm $i$ can ensure that its expected per-period profit is at least:

$$
\bar{\pi}_{i} \equiv\left\{\begin{array}{lll}
\int_{\underline{m}}^{K}\left(m-K_{-i}\right) g(m) d m+k_{i} \int_{K}^{\bar{m}} g(m) d m & \text { if } \quad \underline{m}<K<\bar{m} \\
\widehat{m}-K_{-i} & \text { if } \quad \bar{m} \leq K .
\end{array}\right.
$$

This defines firm $i$ 's minimax payoff. The intuition is that the firm with strictly the highest price expects to supply its full capacity if the realisation of market demand exceeds total capacity, but it expects to supply the residual demand otherwise. It follows from this that the largest firm will never set a price below $\underline{p} \equiv \bar{\pi}_{n} / k_{n}$ in an attempt to be the lowest-priced firm. This implies

\footnotetext{
${ }^{8}$ This analysis is available from the authors upon request.
} 
that the smaller firms $i<n$ can sell their full capacity with certainty by charging a price slightly below $\underline{p}$ to obtain a profit of $k_{i} \underline{p} \geq \bar{\pi}_{i}$. Consequently, the mixed strategy Nash equilibrium profits are given by $\pi_{i}^{N}\left(k_{n}\right)=k_{i} \underline{p}$. This is equivalent to (2), where Assumption 1 is sufficient to ensure that these are nonnegative for all $i$. The lower bound of the support is $\underline{p}$.

\section{Monitoring with Asymmetries}

In this section, we analyse the repeated game. We first show that there is some public information that firms can condition their play on, and find when monitoring is perfect or imperfect. We then solve the game and compare the results for alternative capacity distributions. Henceforth, we impose $\underline{m}<K$, as collusion is unnecessary otherwise from Lemma 1 .

\subsection{Information and monitoring}

Under our assumptions, repetitions of the stage game generate private and public information histories. For instance, the private history of firm $i$ in period $t$ is the sequence of its past prices and sales, denoted $z_{i}^{t} \equiv\left(p_{i 0}, s_{i 0} ; \ldots ; p_{i t-1}, s_{i t-1}\right)$. In contrast, a public history is the sequence of information that is observed by all firms, regardless of their actions. In this subsection, we show that the fact that each firm observes its own sales implies that all firms will always know when at least one firm's sales are below some firm-specific "trigger level". As we discuss below, firms can then use public strategies in which they condition their play on this public information. Formally, let firm $i$ 's trigger level be of the form $\underline{s}_{i}(\mu) \equiv \frac{k_{i}}{K} \mu$ for all $i$ and consider the history $h^{t}=\left(y_{0}, y_{1}, \ldots, y_{t-1}\right)$ where, for all $\tau=\{0,1, \ldots, t-1\}$ :

$$
y_{\tau}= \begin{cases}\bar{y} & \text { if } s_{i \tau}\left(p_{i \tau}, \mathbf{p}_{-i \tau} ; m_{\tau}\right)>\underline{s}_{i}(\mu) \forall i \\ \underline{y} & \text { otherwise. }\end{cases}
$$

This says that $y_{\tau}=\bar{y}$ if all firms' sales in period $\tau$ exceed their trigger levels, but $y_{\tau}=\underline{y}$ if at least one firm's sales does not.

We wish to establish that $h^{t}$ is a public history if $\mu \geq m^{*}\left(k_{1}, \bar{m}\right) \equiv \min \left\{\frac{K\left(\bar{m}-k_{1}\right)}{K_{-1}}, K\right\}$. This requires that $y_{\tau}$ is common knowledge for all $\tau$, for any $z_{i}^{t}$. First, suppose $\underline{s}_{i}(\mu) \geq k_{i}$ such that $\mu \geq K$ for any $\bar{m}>\underline{m}$. For any such case, $h^{t}$ is a public history because the trigger levels are so high that all firms' sales can never exceed them for any prices. Hence, $y_{\tau}=\underline{y}$ for all $\tau$. Next, suppose $\underline{s}_{i}(\mu) \in\left[\underline{s}_{i}\left(m^{*}\left(k_{1}, \bar{m}\right)\right), k_{i}\right)$ such that $\mu \in\left[\frac{K\left(\bar{m}-k_{1}\right)}{K_{-1}}, K\right)$, which requires $\bar{m}<K$. In this case, it is possible for firms to receive sales above their trigger levels, since $\underline{s}_{i}(\mu)<k_{i}$, but 
each firm's sales will never do so if the firm has been undercut on price. For instance, for any nonempty set of rivals with a price strictly below $p^{\max }, \Omega\left(p^{\max }\right)$, the sales of firm $j \in \Omega\left(p^{\max }\right)$ are $s_{j}=k_{j}$ and, given $\bar{m}<K$, the sales of firm $i$ with $p_{i}=p^{\max } \leq 1$ are:

$$
s_{i}=\frac{k_{i}\left(m_{t}-\sum_{j \in \Omega\left(p^{\max }\right)} k_{j}\right)}{K-\sum_{j \in \Omega\left(p^{\max }\right)} k_{j}} \leq \frac{k_{i}\left(\bar{m}-k_{1}\right)}{K_{-1}}=\underline{s}_{i}\left(m^{*}\left(k_{1}, \bar{m}\right)\right) \leq \underline{s}_{i}(\mu)<k_{i},
$$

from (1). It then follows that $h^{t}$ is a public history for any $\mu \in\left[\frac{K\left(\bar{m}-k_{1}\right)}{K_{-1}}, K\right)$ for the following reasons. If firms set a common price $p \leq 1$, then either all firms' sales will exceed their trigger levels or they all will not. Yet, as has just been demonstrated, if firms do not set such a common price, then the sales of the highest-priced firms will not exceed their trigger levels, and their lower-priced rivals will supply their full capacities. ${ }^{9}$ Any low-priced firm that supplies its full capacity knows, from (1), that its price is strictly below the highest in the market. Furthermore, it also knows that this implies that the highest-priced firms' sales are below their respective trigger levels. Finally, note that $h^{t}$ is not a public history if $\underline{s}_{i}(\mu)<\underline{s}_{i}\left(m^{*}\left(k_{1}, \bar{m}\right)\right)$ for any $\bar{m}>\underline{m}$. The reason is that firms can receive sales above their trigger levels when firms set a common price and when they have been undercut on price, from (1). Consequently, if firms do not set a common price, then a low-priced firm that supplies its full capacity can no longer infer from its sales whether the sales of the highest-priced firms are below their respective trigger levels.

The above implies that, for any $\mu \geq m^{*}\left(k_{1}, \bar{m}\right)$, there exists some public information that allows firms to make inferences about the behaviour of their rivals. In particular, each firm knows that all firms' sales will exceed their trigger levels, such that $y=\bar{y}$, if $p_{j}=p \leq 1$ for all $j$ and if $m>\mu \geq m^{*}\left(k_{1}, \bar{m}\right)$; otherwise, at least one firm's sales will not exceed its trigger level, so $y=\underline{y}$. It follows from this that if $\underline{m}>m^{*}\left(k_{1}, \bar{m}\right)$, then firms can perfectly monitor a strategy in which all firms set a common collusive price. This is due to the fact that each firm would receive sales below $\underline{s}_{i}\left(m^{*}\left(k_{1}, \bar{m}\right)\right)$ only if it has been undercut. In contrast, if $\underline{m} \leq m^{*}\left(k_{1}, \bar{m}\right)$, then there is imperfect monitoring for any $\mu \geq m^{*}\left(k_{1}, \bar{m}\right)$. The reason can be understood by considering $\operatorname{Pr}\left(\underline{y} \mid p_{i}, \mathbf{p}_{-i}\right)$ which denotes the probability of observing $\underline{y}$ if firm $i$ sets $p_{i}$ and its rivals price according to $\mathbf{p}_{-i}$. For the case of $\mu \geq m^{*}\left(k_{1}, \bar{m}\right) \geq \underline{m}$ :

$$
\operatorname{Pr}\left(\underline{y} \mid p_{i}, \mathbf{p}_{-i}\right)= \begin{cases}\int_{\underline{m}}^{\min \{\mu, \bar{m}\}} g(m) d m \in[0,1] & \text { if } p_{j}=p \forall j \\ 1 & \text { otherwise. }\end{cases}
$$

\footnotetext{
${ }^{9}$ If any firms' prices are above 1 , then they will receive zero sales, which is below their trigger levels. In this case, only the firms whose prices do not exceed 1 will supply their full capacities.
} 
This says that a firm's sales can be below its trigger level if the realisation of market demand is sufficiently low, even when firms set a common price. Thus, for such an outcome colluding firms face a non-trivial signal extraction problem: each firm does not know whether the realisation of market demand was unluckily low or whether at least one rival has undercut them.

Proposition 1 finds the conditions for perfect and imperfect monitoring in terms of the maximum market demand, holding the minimum market demand constant.

Proposition 1. For any given $n \geq 2, K_{-1} \leq \underline{m}<K$, and $\delta \in(0,1)$, there exists a unique level of market demand, $\underline{x}\left(k_{1}\right) \equiv \underline{m}+k_{1}\left(\frac{K-\underline{m}}{K}\right) \in(\underline{m}, K)$, such that if $\bar{m} \in\left(\underline{m}, \underline{x}\left(k_{1}\right)\right)$, then monitoring can be perfect. Otherwise, there is imperfect monitoring.

Monitoring can be perfect if the fluctuations in market demand are sufficiently small, otherwise there is imperfect monitoring. The critical level $\underline{x}\left(k_{1}\right)$ is strictly increasing in the capacity of the smallest firm, $k_{1}$. The reason is that deviations by the smallest firm are most difficult to detect, from (5), and it follows from this that detecting a deviation is less difficult when the smallest firm is larger. Consequently, if it is just possible for a firm to infer that the smallest firm has not deviated for a given level of $\bar{m}$, then it is also possible for the same level of $\bar{m}$ if the smallest firm has more capacity. Thus, deviations can be detected perfectly for a wider range of fluctuations in market demand when the smallest firm is larger.

Finally, we have so far considered the public information that firms can infer from their privately observed sales. Before moving on, we should discuss two possible scenarios in which a firm's sales can provide it with private information that is not common knowledge among all firms. In either case though, it should be noted that any such private information is not payoff relevant if rivals follow public strategies. Thus, it will not be possible for a firm to use its private information to gain by deviating from an equilibrium in public strategies. The first case is when a firm knows for sure that it has been undercut. This occurs if firm $i$ 's sales are inconsistent with all firms setting a common price, $s_{i}<\frac{k_{i}}{K} \underline{m}$ for some $i$. Such information is not common knowledge if monitoring is imperfect, because the deviants $j \neq i$ would be unaware of the specific levels of its rivals' sales: they simply know that at least one rival's sales are below its trigger level. The second case is when the smallest firm knows for sure that all firms have set a common price, but its rivals $i>1$ are uncertain as to whether the smallest firm has undercut them. This may occur if firm 1 is strictly the smallest firm and if fluctuations in market demand are not large, such that $\bar{m}<K$. In such a case, the highest possible sales of the smallest firm if it is undercut are $\frac{k_{1}}{K_{-2}}\left(\bar{m}-k_{2}\right)<\underline{s}_{i}\left(m^{*}\left(k_{1}, \bar{m}\right)\right)$. Thus, if the smallest firm's sales are below 
$\underline{s}_{i}\left(m^{*}\left(k_{1}, \bar{m}\right)\right)$ yet above $\frac{k_{1}}{K_{-2}}\left(\bar{m}-k_{2}\right)$, then it knows for sure that all firms have set a common price. Nevertheless, the fact that the smallest firm's sales will be below its trigger level for any $\mu \geq m^{*}\left(k_{1}, \bar{m}\right)$ will inform it that its rivals' sales are also below their trigger levels.

\subsection{Optimal collusive equilibrium profits}

We now solve the repeated game restricting attention to sequential equilibria in public strategies, in which firms condition their play only on the public history. Such equilibria are known as perfect public equilibria (PPE) (see Fudenberg and Tirole, 1994, p.187-191). We solve the model using two seemingly different approaches. First, in the main body of the paper, we restrict attention to a particular class of PPE in which, similar to Green and Porter (1984) and Tirole (1988), firms punish each other by reverting to the static Nash equilibrium for a fixed number of periods, if they receive a bad signal in a collusive period. The strategy profile for this approach is formally described below and we refer to it as trigger-sales strategies. Second, given that restricting attention to trigger-sales strategies leaves open the question of whether there are other PPE with higher profits, we solve for the set of PPE in the online appendix using the techniques of Abreu et al. (1986, 1990). This appendix shows that trigger-sales strategies are optimal equilibrium strategies in that they support the maximal PPE payoffs and they generate the lowest critical discount factor.

Trigger-sales strategies are formally defined as follows. There are 'collusive phases' and 'punishment phases'. Suppose period $t$ is in a collusive phase. In any such period, a firm should set the collusive price, $p^{c}>\underline{p}$. If $y_{t}=\bar{y}$, such that all firms received sales above their trigger levels, then the collusive phase continues into the next period $t+1$. If $y_{t}=\underline{y}$, such that at least one firm received sales below its trigger level, then firms enter a punishment phase in the next period $t+1$. In the punishment phase, each firm should play the static Nash equilibrium for $T$ periods, after which a new collusive phase begins. This sequence repeats in any future collusive phase.

Denote firm $i$ 's expected (normalised) profit in a collusive phase as $k_{i} V^{c}$ and its expected (normalised) profit at the start of a punishment phase as $k_{i} V^{p}$. If all firms follow trigger-sales strategies, then:

$$
\begin{aligned}
& k_{i} V^{c}=(1-\delta) \pi_{i}\left(p^{c}\right)+\delta\left[\left(1-\operatorname{Pr}\left(\underline{y} \mid p^{c}\right)\right) k_{i} V^{c}+\operatorname{Pr}\left(\underline{y} \mid p^{c}\right) k_{i} V^{p}\right] \\
& k_{i} V^{p}=(1-\delta) \sum_{t=0}^{T-1} \delta^{t} \pi_{i}^{N}\left(k_{n}\right)+\delta^{T} k_{i} V^{c}
\end{aligned}
$$


for all $i$, where $\operatorname{Pr}\left(\underline{y} \mid p^{c}\right)=G(\mu)$ from (6). Substituting $k_{i} V^{p}$ into $k_{i} V^{c}$ and solving yields:

$$
k_{i} V^{c}=\pi_{i}^{N}\left(k_{n}\right)+\frac{(1-\delta)}{1-\delta+G(\mu) \delta\left(1-\delta^{T}\right)}\left(\pi_{i}\left(p^{c}\right)-\pi_{i}^{N}\left(k_{n}\right)\right),
$$

where it is then straightforward to check that $\pi_{i}\left(p^{c}\right) \geq k_{i} V^{c}>k_{i} V^{p}$ for any $T>0$ and that $k_{i} V^{p}>\pi_{i}^{N}\left(k_{n}\right)$ for any $T<\infty$.

The profile of trigger-sales strategies is a PPE if, for each date $t$ and any history $h^{t}$, the strategies yield a Nash equilibrium from that date on. We say that collusion under trigger-sales strategies is not sustainable if no such equilibrium strategies exist. Given firms play the static Nash equilibrium during each period of the punishment phase, it is clear that they have no incentive to deviate in any such periods. Thus, we need only consider deviations during collusive phases, in which case $\operatorname{Pr}\left(\underline{y} \mid p_{i}, p^{c}\right)=1$ for any $p_{i} \neq p^{c}$ from (6). The incentive compatibility constraint (ICC) for any firm $i$ is as follows:

$$
\begin{aligned}
k_{i} V^{c} & \geq(1-\delta) k_{i} p^{c}+\delta k_{i} V^{p} \\
& \geq\left(\frac{1-\delta}{1-\delta^{T}}\right) k_{i} p^{c}+\delta \pi_{i}^{N}\left(k_{n}\right) .
\end{aligned}
$$

This says that firm $i$ will not deviate in any period in a collusive phase if it cannot gain by marginally undercutting $p^{c}>\underline{p}$ to supply its full capacity $k_{i} .{ }^{10}$ Notice for all $\pi_{i}\left(p^{c}\right)>\pi_{i}^{N}\left(k_{n}\right)$ that lowering $\mu$ towards $m^{*}\left(k_{1}, \bar{m}\right)$ increases $k_{i} V^{c}$, from (7), and it slackens the ICC in (8). Consequently, it is optimal for firms to set $\mu=m^{*}\left(k_{1}, \bar{m}\right)$, such that the trigger levels are determined by the largest sales firms $i>1$ can make if all such firms set the same price and firm 1 undercuts to sell its full capacity. Then it is easy to check that (8) is never satisfied when the maximum market demand is greater than total capacity, $\bar{m} \geq K$, because $G\left(m^{*}\left(k_{1}, \bar{m}\right)\right)=1$ from (6). Thus, collusion under trigger-sales strategies is not sustainable if $\bar{m} \geq K$, so we can henceforth focus on the case where $\bar{m}<K$.

Substituting $k_{i} V^{c}$ into (8), then rearranging yields:

$$
\left(1-G\left(m^{*}\left(k_{1}, \bar{m}\right)\right)\right) K\left(p^{c}-\underline{p}\right)-\frac{(K-\widehat{m}) p^{c}}{\delta} \geq \delta^{T}\left[\left(1-G\left(m^{*}\left(k_{1}, \bar{m}\right)\right)\right) K\left(p^{c}-\underline{p}\right)-(K-\widehat{m}) p^{c}\right] .
$$

It follows from the fact that (9) is independent of $k_{i}$ that if the ICC holds for firm $i$, then it also holds for all other firms $j \neq i$. This implies that, under the proportional allocation rule, each firm has the same incentive to deviate as its rivals despite potential asymmetries. Furthermore, note

\footnotetext{
${ }^{10}$ It follows from Lemma 1 that firm $i$ 's optimal deviation is to undercut $p^{c}>p$ for all $i$. Furthermore, note that $p^{c}>\underline{p}$ is a necessary condition for firms to attain collusive profits per-period greater than the static Nash equilibrium profit.
} 
that the left-hand side of (9) is strictly less than the expression in square brackets on the righthand side for all $\delta<1$. Consequently, (9) can only hold if both are nonnegative, since $\delta^{T} \in(0,1]$ for all $T \in[0, \infty)$. Thus, similar to Green and Porter (1984) and Tirole (1988), it follows from (9) that there are three necessary conditions for the profile of triggers-sales strategies to be a PPE. First, the length of the punishment phase must be sufficiently long, where the critical duration, denoted $T^{*}\left(k_{1}, k_{n}, p^{c}\right)$, is implicitly defined by the level of $T$ where (9) holds with equality. ${ }^{11}$ Second, firms must also be sufficiently patient, such that:

$$
\delta \geq \frac{(K-\widehat{m}) p^{c}}{\left(1-G\left(m^{*}\left(k_{1}, \bar{m}\right)\right)\right) K\left(p^{c}-\underline{p}\right)} \equiv \delta^{*}\left(k_{1}, k_{n}, p^{c}\right),
$$

in which case the left-hand side of (9) is nonnegative, such that the ICC holds as $T \rightarrow \infty$. This implies that if firms are not sufficiently patient, then even a punishment phase that lasts an infinite number of periods is insufficient to outweigh the short-term benefit from deviating. Furthermore, note that the critical punishment phase duration $T^{*}\left(k_{1}, k_{n}, p^{c}\right)<\infty$ for any $\delta>$ $\delta^{*}\left(k_{1}, k_{n}, p^{c}\right)$ and $T^{*}\left(k_{1}, k_{n}, p^{c}\right) \rightarrow \infty$ if $\delta=\delta^{*}\left(k_{1}, k_{n}, p^{c}\right)$. Third, the probability of receiving a bad signal must be sufficiently low, where:

$$
G\left(m^{*}\left(k_{1}, \bar{m}\right)\right)<1-\frac{(K-\widehat{m}) p^{c}}{K\left(p^{c}-\underline{p}\right)}
$$

such that the expression in square brackets in (9) is positive. Note that (11) ensures $\delta^{*}\left(k_{1}, k_{n}, p^{c}\right)<$ 1 , which implies that if this condition is not met, then the firms are not sufficiently patient for any $\delta<1$, even if a punishment phase lasts an infinite number of periods.

Proposition 2 solves for the optimal PPE profits under trigger-sales strategies. We refer to this as collusion under imperfect monitoring.

Proposition 2. For any given $n \geq 2$ and $K_{-1} \leq \underline{m}<K$, there exists a unique level of market demand, $\bar{x}\left(k_{1}, k_{n}\right) \in\left(\underline{x}\left(k_{1}\right), K\right)$, that solves $G\left(m^{*}\left(k_{1}, \bar{x}\left(k_{1}, k_{n}\right)\right)\right)=\frac{K_{-n}}{K}<1$, such that, if $\bar{m} \in\left[\underline{x}\left(k_{1}\right), \bar{x}\left(k_{1}, k_{n}\right)\right)$ and if $\delta \geq \delta^{*}\left(k_{1}, k_{n}\right) \equiv \frac{1}{1-G\left(m^{*}\left(k_{1}, \bar{m}\right)\right)} \frac{k_{n}}{K} \in\left(\frac{k_{n}}{K}, 1\right)$, then firm $i$ 's optimal PPE profits under trigger-sales strategies are:

$$
k_{i} V^{*}=\frac{k_{i}}{K}\left(\frac{\widehat{m}-G\left(m^{*}\left(k_{1}, \bar{m}\right)\right) K}{1-G\left(m^{*}\left(k_{1}, \bar{m}\right)\right)}\right) \in\left(\pi_{i}^{N}\left(k_{n}\right), \frac{k_{i}}{K} \widehat{m}\right) \forall i .
$$

Otherwise, collusion under trigger-sales strategies is not sustainable.

\footnotetext{
${ }^{11}$ Although $T^{*}\left(k_{1}, k_{n}, p^{c}\right)$ may not be an integer, the expected punishment phase duration could still equal this if firms could vary the length of punishment phases using a publicly observable randomisation device.
} 
This says that, if the necessary conditions (10) and (11) are satisfied, then the optimal PPE profits under trigger-sales strategies have the firms set the monopoly price during a collusive phase and the optimal punishment phase duration is $T^{*}\left(k_{1}, k_{n}, p^{m}\right)$ such that the ICC (9) is binding with no slack. Despite the fact that firms set the monopoly price during collusive phases, the sum of firms' equilibrium profits is below the monopoly profit, because punishment phases occur on the equilibrium path. Finally, if firms set a collusive price below the monopoly price, it not only lowers profits but it also raises the critical discount factor. Thus, either the profile of trigger-sales strategies, with firms setting the monopoly price during collusive phases, is a PPE or it is not an equilibrium strategy profile at any collusive price.

Next, we turn our attention to the case of perfect monitoring, where $G\left(m^{*}\left(k_{1}, \bar{m}\right)\right)=0$. In this case, any PPE is also a subgame perfect Nash equilibrium (SPNE) and, as we explain further in a moment, we can easily generate the optimal SPNE profits by letting the punishment phase last an infinite number of periods, such that $T \rightarrow \infty$. Thus, the optimal SPNE profits are summarised by the following corollary. We refer to this as collusion under perfect monitoring.

Corollary 1. For any given $n \geq 2$ and $K_{-1} \leq \underline{m}<\bar{m} \leq \underline{x}\left(k_{1}\right)$, there exists a unique discount factor $\underline{\delta}^{*}\left(k_{n}\right) \equiv \frac{k_{n}}{K} \in\left(0, \frac{m}{K}\right]$, such that if $\delta \geq \underline{\delta}^{*}\left(k_{n}\right)$, then firm i's optimal SPNE profits under trigger-sales strategies are:

$$
k_{i} V^{*}=\frac{k_{i}}{K} \widehat{m}>\pi_{i}^{N}\left(k_{n}\right) \forall i .
$$

Otherwise, collusion under trigger-sales strategies is not sustainable.

The firms divide the monopoly profits between them if they are sufficiently patient. The equilibrium profits are highest and the critical discount factor is lowest when the firms set the monopoly price. The critical discount factor is the same as in Compte et al. (2002) and it also coincides with the lowest possible discount factor that sustains collusion given the proportional allocation rule. The reason is that, as showed by Lambson (1994), the optimal punishments under the proportional allocation rule are such that the largest firm receives the stream of profits from its minimax strategy. In our setting, this is the case as $T \rightarrow \infty$, because in each period of the punishment phase the firms receive the static Nash equilibrium profits, which for the largest firm is equivalent to its minimax payoff. Thus, it is not possible to lower the critical discount factor below this level, given the proportional allocation rule.

These results are brought together in Figure 1. It highlights that the critical discount factor under imperfect monitoring, $\delta^{*}\left(k_{1}, k_{n}\right)$, converges to the critical level under perfect monitoring, 


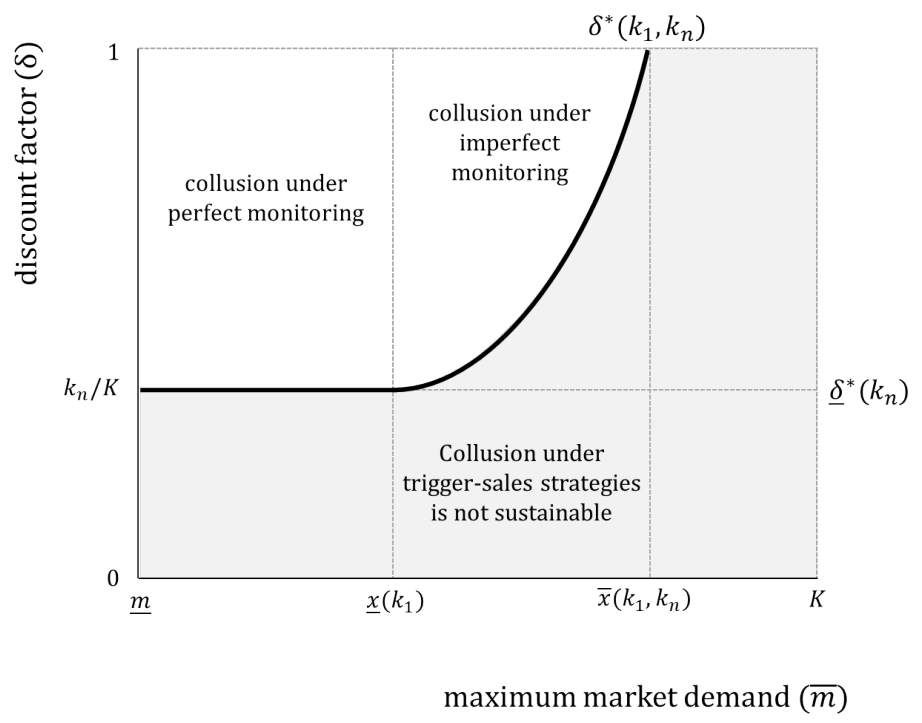

Figure 1: Parameter space of collusion

$\underline{\delta}^{*}\left(k_{n}\right)$, at $\bar{m}=\underline{x}\left(k_{1}\right)$, but it is strictly above $\underline{\delta}^{*}\left(k_{n}\right)$ for any higher maximum market demand. The optimal equilibrium profits under trigger-sales strategies, $k_{i} V^{*}$, equal the monopoly level at or below $\underline{x}\left(k_{1}\right)$ for all $\delta \geq \underline{\delta}^{*}\left(k_{n}\right)$, and they equal the static Nash equilibrium profits at $\bar{m}=\bar{x}\left(k_{1}, k_{n}\right)$ where $\delta^{*}\left(k_{1}, k_{n}\right)=1$. Furthermore, assuming a mean-preserving spread, they are strictly decreasing in $\bar{m}$ between $\underline{x}\left(k_{1}\right)$ and $\bar{x}\left(k_{1}, k_{n}\right)$. Before moving on, the reader may wish to check the online appendix, where we use the techniques of Abreu et al. $(1986,1990)$ to show that the optimal equilibrium profits under trigger-sales strategies are the maximal PPE payoffs. Thus, henceforth we refer to them as the optimal equilibrium profits.

\subsection{Comparing capacity distributions}

We want to analyse the effects of mergers in our setting. Before doing so, it is helpful to get a clear understanding of how the capacity distribution affects collusion by analysing changes in the capacity distribution when the number of firms and the total capacity are held constant. This implies that any such changes in the capacity of a given firm will require capacity to be reallocated from a rival. For example, increasing the size of the smallest firm in a duopoly implies that the capacity of the largest firm decreases. Thus, throughout this subsection, we assume that when the capacity of firm $j$ changes by a small amount, other things equal, the capacities of the other firms change to the extent that $\frac{\partial k_{i}}{\partial k_{j}} \in[-1,0]$ for all $i \neq j$, where $\sum_{i \neq j} \frac{\partial k_{i}}{\partial k_{j}}=-1$. 
However, in what follows we restrict the discussion to capacity reallocations that directly affect the equilibrium analysis, and this is the case for changes to the capacity of the smallest firm or the largest firm.

Proposition 3 analyses the effects of reallocating capacity among the firms on the critical discount factor, which ensures that the ICC holds as $T \rightarrow \infty$.

Proposition 3. For any given $n \geq 2$ and $K_{-1} \leq \underline{m}<K$ :

i) if $\bar{m} \in\left[\underline{m}, \underline{x}\left(k_{1}\right)\right)$, then $\underline{\delta}^{*}\left(k_{n}\right)$ is strictly increasing in the capacity of the largest firm, $k_{n}$;

ii) if $\bar{m} \in\left[\underline{x}\left(k_{1}\right), \bar{x}\left(k_{1}, k_{n}\right)\right)$, then $\delta^{*}\left(k_{1}, k_{n}\right)$ is strictly increasing in the capacity of the largest firm, $k_{n}$, and strictly decreasing in the capacity of the smallest firm, $k_{1}$.

Consistent with Compte et al. (2002), increasing the size of the largest firm hinders collusion. The reason is that a punishment that lasts an infinite number of periods is weaker when the largest firm is larger, because under Assumption 1 the static Nash equilibrium profits increase for each firm, so the critical discount factor rises. In contrast to Compte et al. (2002), increasing the size the smallest firm facilitates collusion. This is due to the fact that firms can monitor an agreement more successfully when the smallest firm is larger, because it is less likely that firms' sales will be below their trigger levels when they set a common price. This does not affect the critical discount factor under perfect monitoring but, as we saw in section 3.1, it does imply that monitoring is perfect for a wider range of fluctuations in market demand. Under imperfect monitoring, it is less likely that a collusive phase will switch to a punishment phase on the equilibrium path when the smallest firm is larger. Consequently, the expected future profits from collusion are higher than before, which implies that a punishment that lasts an infinite number of periods is relatively harsher, so the critical discount factor falls. ${ }^{12}$

Next, we analyse the effects of reallocating capacity among the firms on the optimal equilibrium profits. For convenience, we transform such profits to an average price and compare it to the average static Nash equilibrium price, given by $\widehat{p}^{N}\left(k_{n}\right) \equiv \frac{K}{\hat{m}} \frac{\left(\widehat{m}-K_{-n}\right)}{k_{n}}$ for all $\bar{m}<K$. The average price of the optimal equilibrium profits under perfect monitoring is independent of the capacity distribution, since firms set $p^{m}$ in each period if they are sufficiently patient. So, Proposition 4 investigates the effect of reallocating capacity on the average price associated with the

\footnotetext{
${ }^{12}$ Both results are consistent with the findings of Vasconcelos (2005). The underlying incentives for his results are very different to ours though, as they rely on capacities affecting marginal costs in a setting of perfect observability.
} 
optimal equilibrium profits under imperfect monitoring. We refer to this as the optimal average price, and this is given by $\widehat{p}^{c}\left(k_{1}, \bar{m}\right) \equiv \frac{K}{\widehat{m}} V^{*}$ in expectation, where $\widehat{p}^{N}\left(k_{n}\right)<\widehat{p}^{c}\left(k_{1}, \bar{m}\right)<p^{m}$.

Proposition 4. For any given $n \geq 2, K_{-1} \leq \underline{m}<\underline{x}\left(k_{1}\right)<\bar{m}<\bar{x}\left(k_{1}, k_{n}\right)$ and $\delta \geq \delta^{*}\left(k_{1}, k_{n}\right)$, the optimal average price, $\widehat{p}^{c}\left(k_{1}, \bar{m}\right)$, is strictly increasing in the capacity of the smallest firm, $k_{1}$.

The optimal average price is increasing in the capacity of the smallest firm for two reasons. First, as the capacity of the smallest firm increases, it is less likely that firms' sales will be below their trigger levels when they set a common price. Thus, profits rise on the equilibrium path, other things equal, because collusive phases are less likely to switch to punishment phases than before. Second, such an increase in profits also introduces slack into the ICC. Consequently, the optimal punishment phase duration shortens to ensure that the ICC is binding with no slack, which increases equilibrium profits further.

Surprisingly, the optimal average price is independent of the capacity of the largest firm, when the capacity of the smallest firm is held constant. This is due to the fact that an increase in the capacity of the largest firm raises the static Nash equilibrium profits under Assumption 1, and this causes two counteracting effects on the collusive profits that perfectly offset each other. First, there is a direct effect in that higher static Nash equilibrium profits raise collusive profits on the equilibrium path, other things equal. Second, higher static Nash equilibrium profits make the punishment relatively weaker than before, so the ICC is tighter. Consequently, there is indirect effect in that profits on the equilibrium path fall, because the optimal punishment phase duration lengthens to ensure that the ICC is binding with no slack. This second effect cancels out the first under the proportional allocation rule, implying the size of the largest firm has no effect on the optimal average price.

It follows from the above analysis that asymmetries hinder collusion under perfect and imperfect monitoring. In summary, Proposition 3 implies that the parameter space of collusion is greatest when firms' capacities are symmetric, because the punishment is harshest when the largest firm is as small as possible, and since monitoring is most successful when the smallest firm is as large as possible. The latter also implies that the optimal average price is higher if firms are symmetric from Proposition 4. Furthermore, since the optimal average price is independent of the size of the largest firm, it follows that the optimal average price is highest for a symmetric duopoly and that, for example, it would be higher for a symmetric triopoly than an asymmetric duopoly with $k_{1}<K / 3$. 
Despite the fact that symmetry is ideal for collusion, Proposition 5 next shows that the competitive prices of asymmetric capacity distributions can be higher on average than the optimal collusive prices of less asymmetric capacity distributions. To prove this result, we compare the optimal average price of one distribution, $\left(k_{1}, k_{n}\right)$, to the static Nash equilibrium average price of another, denoted $\left(k_{1}^{\prime}, k_{n}^{\prime}\right)$.

Proposition 5. For any given $n \geq 2, K_{-1} \leq \underline{m}<K$ and $\delta \geq \delta^{*}\left(k_{1}, k_{n}\right)$, if $k_{n}^{\prime}>k_{n}$, such that $k_{1}^{\prime} \leq k_{1}$, then there exists a unique level of market demand, $\bar{x}\left(k_{1}, k_{n}^{\prime}\right) \in\left(\underline{x}\left(k_{1}\right), \bar{x}\left(k_{1}, k_{n}\right)\right)$, that solves $G\left(m^{*}\left(k_{1}, \bar{x}\left(k_{1}, k_{n}^{\prime}\right)\right)\right)=1-\frac{k_{n}^{\prime}}{K}<1$, where if $\bar{m} \in\left(\bar{x}\left(k_{1}, k_{n}^{\prime}\right), \bar{x}\left(k_{1}, k_{n}\right)\right)$, then the static Nash equilibrium average price of $\left(k_{1}^{\prime}, k_{n}^{\prime}\right)$ is strictly greater than the optimal average price of $\left(k_{1}, k_{n}\right), \widehat{p}^{N}\left(k_{n}^{\prime}\right)>\widehat{p}^{c}\left(k_{1}, \bar{m}\right)$.

This says that if fluctuations in market demand are sufficiently large, then the competitive prices of asymmetric capacity distributions are higher on average than the optimal collusive prices of less asymmetric capacity distributions. The intuition is that an increase in the maximum market demand raises the likelihood that firms' sales will be below their trigger levels when firms set a common price. Thus, punishment periods are expected to occur on the equilibrium path more often than before. As a result, the optimal average price of $\left(k_{1}, k_{n}\right)$ falls towards its corresponding static Nash equilibrium average price as the maximum market demand increases towards the critical level $\bar{x}\left(k_{1}, k_{n}\right)$. Yet, the average static Nash equilibrium price is strictly increasing in the capacity of the largest firm, $k_{n}$. So, consider an alternative distribution $\left(k_{1}^{\prime}, k_{n}^{\prime}\right)$ that is more asymmetric than the original in the sense that $k_{n}^{\prime}>k_{n}$ (so $k_{1}^{\prime} \leq k_{1}$ ). It follows that if the maximum market demand is sufficiently close to $\bar{x}\left(k_{1}, k_{n}\right)$, then $\left(k_{1}^{\prime}, k_{n}^{\prime}\right)$ will have a higher average static Nash equilibrium price than the optimal average price of $\left(k_{1}, k_{n}\right)$. The critical level $\bar{x}\left(k_{1}, k_{n}^{\prime}\right)$ is the point at which $\widehat{p}^{c}\left(k_{1}, \bar{m}\right)=\widehat{p}^{N}\left(k_{n}^{\prime}\right)$ for all $\delta \geq \delta^{*}\left(k_{1}, k_{n}\right)$. Furthermore, the condition that the maximum market demand exceeds $\bar{x}\left(k_{1}, k_{n}^{\prime}\right)$ guarantees that collusion under trigger-sales strategies is not sustainable for $\left(k_{1}^{\prime}, k_{n}^{\prime}\right)$. This is due to the fact that collusion under trigger-sales strategies requires that the maximum market demand is below $\bar{x}\left(k_{1}^{\prime}, k_{n}^{\prime}\right)$, but this is contradicted since $\bar{x}\left(k_{1}^{\prime}, k_{n}^{\prime}\right) \leq \bar{x}\left(k_{1}, k_{n}^{\prime}\right)<\bar{m}$ for all $k_{1}^{\prime} \leq k_{1}$.

\section{Monitoring and Mergers}

We now use our equilibrium analysis to draw implications for merger policy. A merger in our framework amounts to the merging firms consolidating their capacity, so we draw on the analysis 
of section 3.3. However, the following analysis differs to section 3.3 in that a merger will reduce the numbers of firms and can increase both the size of the smallest and largest firm at the same time. We also consider the firms' incentives to merge, analyse the welfare effects, and discuss the implications for divestment remedies. Following the terminology of Farrell and Shapiro (1990), we henceforth refer to the merging firms as insiders and those not involved in the merger as outsiders. We say that a merger is privately optimal if the sum of insiders' profits post-merger is strictly greater than the sum of their profits pre-merger. Finally, with respect to welfare, we focus on the effects of mergers on consumer surplus for two reasons. First, expected total welfare is independent of the capacity distribution, so mergers do not affect it. Second, ensuring consumer surplus does not fall post-merger is commonly perceived to be the main objective of merger control (see Lyons, 2002).

We are particularly interested in comparing unilateral and coordinated effects in our framework. Such effects have been considered independently of each other in the previous literature. For instance, Compte et al. (2002) and Vasconcelos (2005) analyse models where firms can optimally share the monopoly profits in every future period if collusion is sustainable, and they both focus solely on the coordinated effects of mergers on the critical discount factor. Bos and Harrington (2010) analyse the coordinated effects of mergers on the price of a cartel that does not encompass all firms in the market. They find that mergers that increase the capacity controlled by the cartel can raise the cartel price towards the monopoly level. However, in contrast to our model, they restrict attention to capacity distributions for which there is a unique pure strategy static Nash equilibrium price equal to marginal cost, so unilateral effects are not an issue. Thus, in each of these papers a merger that causes coordinated effects is more harmful to consumer welfare than compared with an alternative that causes unilateral effects. This is not always the case in our setting. The reason is that imperfect monitoring does not enable firms to share the monopoly profits in every period, yet the static Nash equilibrium prices will be close to the monopoly level when competition is weak. Consequently, a noncollusive merger outcome that causes unilateral effects can be worse for consumer welfare than a collusive outcome.

Before considering the effects of mergers in our model, we return to discuss the generality of Assumption 1 in the context of mergers. Recall that this restricts the smallest firm's capacity from being too small, $\underline{m} \geq K_{-1}$. In this context, the necessary condition for Assumption 1 to hold is stricter than before, due to the fact that we are only interested in outcomes with at least 2 firms post-merger. Thus, there must be $n>2$ firms pre-merger, in which case the minimum market demand must be greater than $\frac{n-1}{n}$ of the total capacity, $\underline{m} \geq\left(\frac{n-1}{n}\right) K$. The reason 


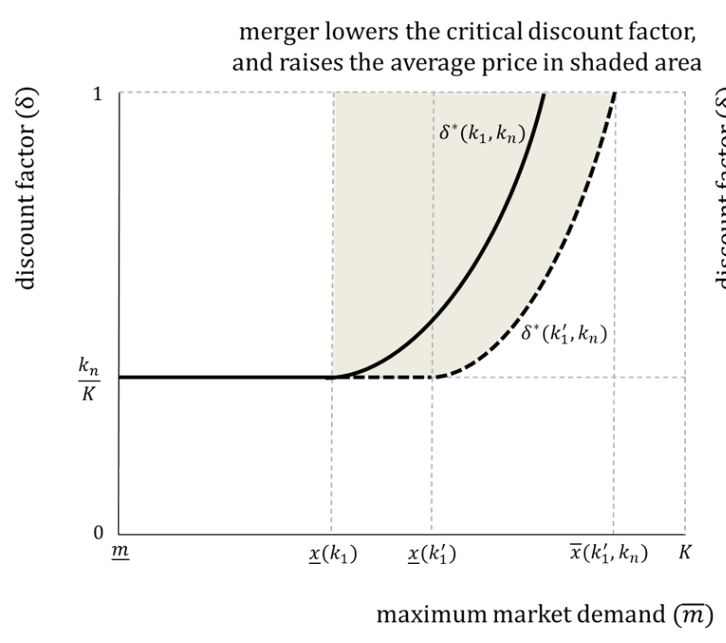

(a) Increasing the smallest firm's capacity $\left(k_{1}^{\prime}>k_{1}, k_{n}^{\prime}=k_{n}\right)$

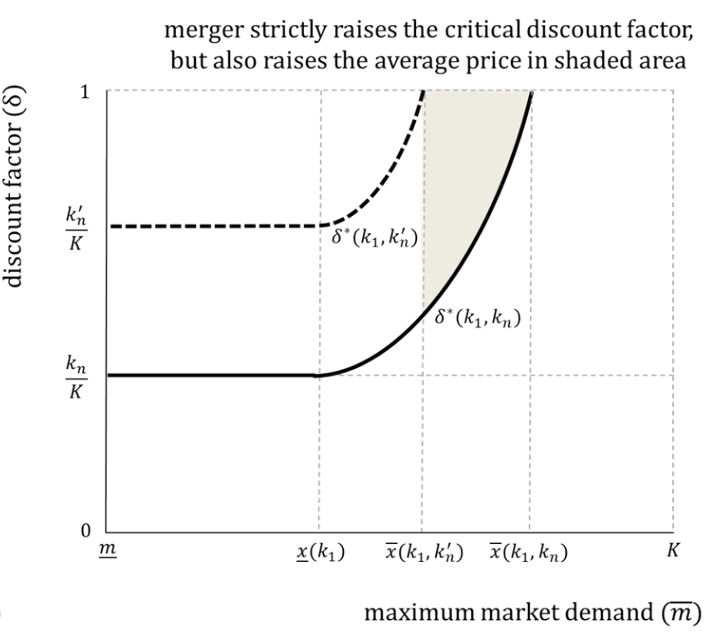

(b) Increasing the largest firm's capacity $\left(k_{1}^{\prime}=k_{1}, k_{n}^{\prime}>k_{n}\right)$

Figure 2: The effects of mergers on the parameter space of collusion

is that the smallest firm's capacity can be no larger pre-merger than for a symmetric capacity distribution, $k_{1}=K / n$. This implies that Assumption 1 is more restrictive when there are more firms in the market pre-merger. However, Assumption 1 is likely to hold for a large number of mergers that raise concerns of collusion pre- and/or post-merger. For example, Davies et al. (2011) found that the European Commission was concerned about post-merger collusion between duopolists in all bar one of the cases that were seriously investigated for tacit collusion between 1990 and 2004 (see also Davies and Olczak, 2010). Consequently, there were usually only three main players pre-merger, such that the necessary condition is $\underline{m} \geq \frac{2}{3} K$. Moreover, given collusion is likely to occur when asymmetries are small, Assumption 1 is especially unrestrictive for cases in which there is collusion pre-merger.

Figure 2 builds on the illustration in Figure 1 to depict the effects of mergers on the parameter space of collusion. It shows how the equilibrium analysis is changed by a merger that either only increases the size of the smallest firm or only increases the size of the largest firm. We discuss each in turn. A merger that increases the size of both the smallest and the largest firm will have a mix of the effects described here. All other mergers will not affect the equilibrium analysis.

A merger that only increases the size of the smallest firm will facilitate collusion. It follows from Proposition 3 that the parameter space of collusion will expand and Proposition 4 implies 
that the average price may also rise post-merger. The parameter space for which such a merger raises the average price is illustrated in the shaded area of Figure 2(a). It shows that the price will rise if collusion is sustainable to some degree post-merger and if either the pre-merger outcome is noncollusive or collusion pre-merger is less than perfect. Furthermore, similar to other models where collusion pre-merger implies firms share the monopoly profits, such a merger has no effect on the average price if there is collusion under perfect monitoring pre- and post-merger. Any such merger that raises the average price is privately optimal and it also strictly increases the profits of the outsiders. This follows since the present discounted value of profits for any set of firms $M$, given an average price $\widehat{p}$, is $\sum_{i \in M} k_{i} \frac{\widehat{m}}{K}\left(\frac{\widehat{p}}{1-\delta}\right)$, where this is higher post-merger only if the average price rises. As a consequence, such a merger will also lower consumer surplus, since the expected consumer surplus per unit is $1-\widehat{p}$. Thus, any collusive outcome that has been facilitated by a merger that only increases the size of the smallest firm is worse than the pre-merger outcome. ${ }^{13}$

A merger that only increases the size of the largest firm will hinder collusion. Proposition 3 implies that the parameter space of collusion will contract. Yet, it follows from Proposition 5 that such a merger may actually increase prices through unilateral effects even if there is collusion premerger. The parameter space for which such a merger raises the average price is illustrated in the shaded area of Figure 2(b). It shows that prices will rise if collusion under imperfect monitoring is sustainable pre-merger but not post-merger and if fluctuations in market demand are sufficiently large. Prices fall for the rest of the area where collusion under imperfect monitoring is sustainable pre-merger but not post-merger. Nevertheless, our model suggests that it is only in the insiders' interests to merge when the average price rises post-merger. This follows since such a merger is privately optimal for any set of firms $M$ if $\sum_{i \in M} k_{i} \frac{\widehat{m}}{K}\left(\frac{\widehat{p}^{N}\left(k_{n}^{\prime}\right)}{1-\delta}\right)>\sum_{i \in M} k_{i} \frac{\widehat{m}}{K}\left(\frac{\widehat{p}^{c}\left(k_{1}, \bar{m}\right)}{1-\delta}\right)$. Consequently, the condition that guarantees the insiders' profits increase post-merger also ensures that the average price rises post-merger. Moreover, the same condition also guarantees that such a merger increases the profits of the outsiders and lowers consumer surplus. It should also be noted for completeness that if there is no collusion pre- or post-merger, then such a merger would increase the average price post-merger through unilateral effects.

Finally, our analysis has important implications for the appropriate divestment remedies of anti-competitive mergers. For instance, an implication of Proposition 5 is that the unilateral

\footnotetext{
${ }^{13}$ It also follows from this that larger firms $i>1$ may increase their profits by divesting capacity to the smallest firm, so that monitoring is easier. Such divestments are not unheard of in actual merger cases (see Compte et al., 2002; and Davies and Olczak, 2010).
} 
effects of a merger can be remedied by a divestment that creates a collusive symmetric outcome. Such a remedy would commonly be rejected by a competition agency, as was the case in the Nestlé/Perrier merger analysed by Compte et al. (2002), for example. To illustrate that such a remedy could eliminate the unilateral effects of a merger, consider a scenario where pre-merger there is a noncollusive triopoly with a capacity distribution of $\left(k_{1}, k_{3}\right)$. Suppose the two largest firms propose to merge and that this would create an asymmetric duopoly $\left(k_{1}, k_{2}^{\prime}\right)$, where $k_{2}^{\prime}>k_{3}$ such that prices will rise through unilateral effects. Consider a remedy of such unilateral effects whereby the merged entity divests some of its capacity to the outsider to create a symmetric duopoly $(k, k)$, where $k_{2}^{\prime}>k>k_{1}$. Proposition 5 implies that if the maximum market demand is sufficiently close to $\bar{x}(k, k)$, then the collusive symmetric duopoly $(k, k)$ will have lower prices and hence higher consumer surplus than the noncollusive unremedied duopoly $\left(k_{1}, k_{2}^{\prime}\right)$, since $\lim _{\bar{m} \rightarrow \bar{x}(k, k)} \widehat{p}^{c}(k, \bar{m})=\widehat{p}^{N}(k)<\widehat{p}^{N}\left(k_{2}^{\prime}\right)$ for all $k_{2}^{\prime}>k$. Thus, here the collusive symmetric duopoly should be preferred to the unremedied post-merger outcome $\left(k_{1}, k_{2}^{\prime}\right)$ from a consumer welfare perspective. Furthermore, similar logic implies that if the largest firm pre-merger has more capacity than in the collusive symmetric duopoly, $k_{3}>k$, then such a divestment can even lower prices compared to pre-merger. In such a case, the collusive symmetric duopoly should actually be preferred to the pre-merger status quo.

\section{Concluding remarks}

We have explored the effects of asymmetries in capacity constraints on collusion in a setting where there is demand uncertainty and where firms never directly observe their rivals' prices and sales. Despite the fact that each firm must monitor the collusive agreement using their privately observed prices and sales, we have shown that firms can perfectly detect deviations if demand fluctuations are sufficiently small. Otherwise, monitoring is imperfect and punishment phases occur on the equilibrium path. Consistent with the previous literature, we found that asymmetries hinder collusion. Yet, we also analysed both the unilateral and coordinated effects of mergers in a unified framework. We showed that if demand fluctuations are sufficiently large, then the (average) competitive prices of asymmetric capacity distributions are actually higher than the optimal (average) collusive prices of less asymmetric capacity distributions.

Our results have three main implications for merger policy. First, although market transparency is rightly an important criterion in the assessment of coordinated effects in practice, our model re-emphasises the fact that a lack of transparency about rivals' prices and sales is 
not a sufficient condition to rule out such effects: firms may be able to monitor a collusive agreement using their private information. Second, while the possible effects of imperfect monitoring are explicitly mentioned in general terms in the most recent US and European horizontal merger guidelines, our model suggests that such monitoring will be difficult in markets where firm asymmetries are large. Third, and most importantly, collusive merger outcomes should not be presumed to be more harmful than more asymmetric noncollusive merger outcomes. A collusive agreement may require sufficiently frequent price wars that actually lead to higher consumer surplus than a more asymmetric outcome in which one firm's market power is strengthened unilaterally. Consequently, it can be appropriate to remedy a merger outcome with a singularly dominant firm by imposing a divestment that creates a symmetric market structure, even if this facilitates collusion under imperfect monitoring. Likewise, it can be inappropriate for a competition authority to remedy a collusive post-merger outcome by imposing a divestment that creates a more asymmetric market structure.

Finally, an important avenue for future research is to develop techniques that can assess accurately in practice whether a collusive merger outcome is better than a noncollusive outcome. We believe that there are two existing methodologies that are a good place to start to address this issue. First, if collusion is expected to be facilitated post-merger, then more advanced merger simulation techniques may enable the likely effects to be simulated. While these techniques have been criticised in the past for not allowing the conduct of firms post-merger to differ from that assumed pre-merger (see Whinston, 2007), recent developments have have gone some way to address this. For example, Davis and Huse (2010) and Ivaldi and Lagos (2016) use the standard simulation methodology of unilateral effects to develop empirical techniques that simulate coordinated effects on the critical discount factor in differentiated goods market under perfect observability. Thus, to be applicable to the current context, these techniques would have to be extended to the case of imperfect monitoring. Second, if the pre-merger status quo is thought to be collusive, then it may be possible to use the screening devices for collusion on premerger data to estimate the extent to which such collusion is imperfect (see Harrington, 2008, for a review of these devices). For example, one such technique, developed by Porter (1983) and Ellison (1994), discovers collusion under imperfect monitoring by finding evidence of price wars (that is, abrupt changes in prices that cannot be explained by fluctuations in cost or demand). Such price wars are inconsistent with models of competition and with perfect collusion, so if there is no evidence of them pre-merger (and price is at or near the monopoly level), then it is likely that welfare will be improved if collusion pre-merger is expected to be destabilised post- 
merger. On the other hand, evidence of frequent or long price wars pre-merger could suggest that collusion is sufficiently imperfect pre-merger that destabilising collusion by enhancing the market power of one firm unilaterally will actually harm welfare.

\section{References}

[1] Abreu, D., Pearce, D. and Stacchetti, E. (1986) "Optimal Cartel Equilibria with Imperfect Monitoring," Journal of Economic Theory, 39(1), 251-269

[2] Abreu, D., Pearce, D. and Stacchetti, E. (1990) "Toward a Theory of Discounted Repeated Games with Imperfect Monitoring," Econometrica, 58(5), 1041-1063

[3] Amelio, A., and Biancini, S. (2010) "Alternating Monopoly and Tacit Collusion," Journal of Industrial Economics, 58(2), 402-423

[4] Bos, I. and Harrington, J. (2010) "Endogenous Cartel Formation with Heterogeneous Firms," RAND Journal of Economics, 41(1), 92-117

[5] Bos, I. and Harrington, J. (2015) "Competition Policy and Cartel Size," International Economic Review, 56(1), 133-153

[6] Compte, O., Jenny, F. and Rey, P. (2002) "Capacity Constraints, Mergers and Collusion," European Economic Review, 46(1), 1-29

[7] Dasgupta, P. and Maskin, E. (1986) "The Existence of Equilibrium in Discontinuous Economic Games, II: Applications" Review of Economic Studies, 53(1), 27-41

[8] Davies, S. and Olczak, M. (2010) "Assessing the Efficacy of Structural Merger Remedies: Choosing Between Theories of Harm?" Review of Industrial Organization, 37(2), 83-99

[9] Davies, S., Olczak, M., and Coles, H. (2011) "Tacit Collusion, Firm Asymmetries and Numbers: Evidence from EC Merger Cases," International Journal of Industrial Organization, 29(2), 221-31

[10] Davis, P. and Huse, C. (2010) "Estimating the 'Coordinated Effects' of Mergers," Competition Commission Working Paper

[11] Ellison, G. (1994) "Theories of Cartel Stability and the Joint Executive Committee," RAND Journal of Economics, 25(1), 37-57 
[12] Fabra, N. (2006) "Collusion with Capacity Constraints over the Business Cycle," International Journal of Industrial Organization, 24(1), 69-81

[13] Farrell, J. and Shapiro, C. (1990) "Horizontal Mergers: An Equilibrium Analysis," American Economic Review, 80(1), 107-126

[14] Fonseca, M. and Normann, H.-T. (2008) "Mergers, Asymmetries and Collusion: Experimental Evidence," Economic Journal, 118(1), 287-400

[15] Fudenberg, D. and Tirole, J. (1994), Game Theory, MIT Press

[16] Gal-Or, E. (1984) "Price Dispersion with Uncertain Demand," International Economic Review, 25(2), 441-457

[17] Green, E. and Porter, R. (1984) "Non-Cooperative Collusion under Imperfect Price Information," Econometrica, 52(1), 87-100

[18] Harrington, J. (2006) "How do Cartels Operate?" Foundations and Trends in Microeconomics, 2(1), 1-105

[19] Harrington, J. (2008) "Detecting Cartels," in Buccirossi, P., (ed.), Handbook in Antitrust Economics, MIT Press

[20] Harrington, J. and Skrzypacz, A. (2007) "Collusion under Monitoring of Sales," RAND Journal of Economics, 38(2), 314-331

[21] Harrington, J. and Skrzypacz, A. (2011) "Private Monitoring and Communication in Cartels: Explaining Recent Collusive Practices," American Economic Review, 101(6), 2425-2449

[22] Hirata, D. "Asymmetric Bertrand-Edgeworth Oligopoly and Mergers," The B.E. Journal of Theoretical Economics, 9(1), 1-25

[23] Ivaldi, M., Jullien, B., Rey, P., Seabright, P., and Tirole, J. (2003a) "The Economics of Tacit Collusion," Report for DG Comp, European Commission

[24] Ivaldi, M., Jullien, B., Rey, P., Seabright, P., and Tirole, J. (2003b) "The Economics of Unilateral Effects," Report for DG Comp, European Commission

[25] Ivaldi, M. and Lagos, V. (2016) "Assessment of Post-Merger Coordinated Effects: Characterization by Simulations," International Journal of Industrial Organization, forthcoming 
[26] Knittel, C. and Lepore, J. (2010) "Tacit Collusion in the Presence of Cyclical Demand and Endogenous Capacity Levels," International Journal of Industrial Organization, 28(2), $131-144$

[27] Kühn, K.-U., (2001) "An Economist's Guide Through the Joint Dominance Jungle," John M. Olin Centre for Law and Economics Working Paper 02-014

[28] Kühn, K.-U., (2004) "The Coordinated Effects of Mergers in Differentiated Product Markets," John M. Olin Centre for Law and Economics Working Paper 04-020

[29] Lambson, E. (1994) "Some Results on Optimal Penal Codes in Asymmetric Bertrand Supergames," Journal of Economic Theory, 62(2), 444-468

[30] Lyons, B. (2002) "Could Politicians be More Right Than Economists? A Theory of Merger Standards," Centre for Competition and Regulation Working Paper 02-1

[31] Motta, M., Polo, M., and Vasconcelos, H. (2003) "Merger Remedies in the European Union: An Overview," in Lévêque, F. and Shelanski, H., (eds.), Merger Remedies in American and European Union Competition Law, Edward Elgar

[32] Porter, R. (1983). "A Study of Cartel Stability: The Joint Executive Committee, 18801886," Bell Journal of Economics, 14(2), 301-314

[33] Röller, L.-H. and Mano, M. (2006) "The Impact of the New Substantive Test in European Merger Control," European Competition Journal, 2(1), 9-28

[34] Staiger, R. and Wolak, F. (1992) "Collusive Pricing with Capacity Constraints in the Presence of Demand Uncertainty," RAND Journal of Economics, 23(2), 203-220

[35] Stigler, G. (1964) "A Theory of Oligopoly," Journal of Political Economy, 72, 44-61

[36] Tirole, J. (1988) The Theory of Industrial Organisation, MIT Press

[37] Vasconcelos, H. (2005) "Tacit Collusion, Cost Asymmetries, and Mergers," RAND Journal of Economics, 36(1), 39-62

[38] Vives, X. (1999). Oligopoly Pricing: Old Ideas and New Tools, MIT Press

[39] Whinston, M. (2007) "Antitrust Policy toward Horizontal Mergers" in Armstrong, M. and Porter, R., (ed.), Handbook of Industrial Organization, North-Holland 


\section{Appendix A}

Proof of Lemma 1. There exists a unique pure strategy Nash equilibrium if $\underline{m} \geq K$, where $\pi_{i}^{N}=k_{i} \forall i$. This follows from $\pi_{i}\left(p_{i}, \mathbf{p}_{-i}\right)=p_{i} k_{i} \forall p_{i} \leq 1$, so the best reply of firm $i$ is $p_{i}=1$ for any $\mathbf{p}_{-i}, \forall i$. There is no pure strategy Nash equilibrium if $\underline{m}<K$. To see this, note that any such candidate equilibrium requires $p_{j}=p \forall j$. Otherwise, firm $i \in \Omega\left(p^{\max }\right)$ has an incentive to increase its price towards $p^{\max }$, from $\pi_{i}\left(p_{i}, \mathbf{p}_{-i}\right)=p_{i} k_{i} \forall p_{i}<p^{\max }$. However, for any $p \in(0,1]$, firm $i$ has an incentive to lower its price, since $\pi_{i}(p-\epsilon, p)>\pi_{i}(p)$ if $\underline{m}<K$, where $\epsilon>0$ but small. Moreover, for $p=0$, firm $i$ has an incentive to raise its price, since Assumption 1 ensures $\pi_{i}(\epsilon, 0)>0 \forall i$.

Nevertheless, if $K>\underline{m} \geq K_{-1}$, the existence of a mixed strategy Nash equilibrium is guaranteed by Thereom 1 of Dasgupta and Maskin (1986). To characterise this equilibrium, let $H_{i}(p)$ denote the probability that firm $i$ charges a price less than or equal to $p$. Below we demonstrate that the equilibrium profits are given by (2) for all $i$ and that:

$$
H_{i}(p)=\frac{1}{k_{i}}\left[\frac{\left(\bar{\pi}_{n}-p k_{n}\right)}{p k_{n}\left(\int_{\underline{m}}^{\min \{K, \bar{m}\}}(m-K) g(m) d m\right)} \prod_{j=1}^{n} k_{j}\right]^{1 /(n-1)},
$$

where $\bar{\pi}_{n}$ is as given in (3). This converges to the analysis in Fonseca and Normann (2008) as $\bar{m} \rightarrow \underline{m}$.

In equilibrium, firm $i$ must receive the following expected profit from charging $p \leq 1$ :

$$
p\left(\prod_{j \neq i} H_{j}(p) \bar{\pi}_{i}+\left(1-\prod_{j \neq i} H_{j}(p)\right) k_{i}\right)=\frac{k_{i}}{k_{n}} \bar{\pi}_{n}, \forall i
$$

where $\prod_{j \neq i} H_{j}(p)$ is the probability that firm $i$ is the highest-priced firm. To solve for the righthand side of (13), notice firm $i$ has no incentive to price below $\bar{\pi}_{i} / k_{i} \equiv \underline{p}_{i}$, where $\underline{p}_{n} \geq \underline{p}_{n-1} \geq$ $\ldots \geq \underline{p}_{1}$. Moreover, any firm $j<n$ can guarantee profits of $\frac{k_{j}}{k_{n}} \bar{\pi}_{n} \geq \bar{\pi}_{j}$ by charging a price marginally below $\underline{p}_{n}$, so all firms have no incentive to price below $\underline{p}_{n}$. Finally, the fact that all firms $j<n$ place positive probability on charging $\underline{p}_{n}$ is necessary and sufficient to ensure $\underline{p}_{n}$ is also the lowest price that firm $n$ will charge. Thus, the lower bound of $H_{i}(p)$ is $\underline{p}=\underline{p}_{n}=\bar{\pi}_{n} / k_{n}$ $\forall i$. Manipulating (13) yields:

$$
H_{i}(p)=\frac{p k_{n}\left(\bar{\pi}_{i}-k_{i}\right)}{\bar{\pi}_{n}-p k_{n}} \prod_{j} H_{j}(p) \frac{1}{k_{i}}
$$

Noting that $\bar{\pi}_{i}-k_{i}=\int_{\underline{m}}^{\min \{K, \bar{m}\}}(m-K) g(m) d m \forall i$ for any $K>\underline{m}$ from (3), it follows from 
(14) that:

$$
\prod_{j} H_{j}(p)=\left[\frac{p k_{n}\left(\int_{\underline{m}}^{\min \{K, \bar{m}\}}(m-K) g(m) d m\right)}{\bar{\pi}_{n}-p k_{n}} \prod_{j} H_{j}(p)\right]^{n} \prod_{l=1}^{n}\left(\frac{1}{k_{l}}\right) .
$$

Thus, solving for $\prod_{j} H_{j}(p)$ and substituting into (14) shows that $H_{i}(p)$ is as claimed in (12).

It follows from (12) that $H_{i}(1) \lesseqgtr 1$ if $\frac{k_{i}^{n-1}}{\prod_{j \neq n} k_{j}} \gtreqless 1$. This has two implications. First, if $\frac{k_{i}^{n-1}}{\prod_{j \neq n} k_{j}} \geq 1$, then firm $i$ randomises over $[\underline{p}, 1]$ and puts mass of $1-H_{i}(1)$ on a price of 1 when the inequality is strict. Note that $\frac{k_{i}^{n-1}}{\prod_{j \neq n} k_{j}}>1$ never holds if $k_{i}=k \forall i$ but always holds for firm $n$ if $k_{n}>k_{1}$. Second, if $\frac{k_{i}^{n-1}}{\prod_{j \neq n} k_{j}}<1$ for some $i<n$, then firm $i$ randomises over $\left[\underline{p}, \bar{p}_{i}\right]$ where $\bar{p}_{i}<1$ solves $H_{i}\left(\bar{p}_{i}\right)=1$. Consequently, the probability distributions of the larger firms with higher upper bounds must be adjusted accordingly. For example, if $\bar{p}_{i}<1$ only for firm 1 (which is the case for any triopoly with $\left.k_{1}<k_{2}\right)$, then the largest $n-1$ firms play with $H_{i}(p)$ adjusted so that $n-1$ replaces $n$ over $\left[\bar{p}_{1}, 1\right]$. Note that $\frac{k_{i}^{n-1}}{\prod_{j \neq n} k_{j}}<1$ never holds if $n=2$ or if $k_{i}=k \forall i$ for any $n \geq 2$.

Proof of Proposition 1. There can be perfect monitoring if $\underline{m}>m^{*}\left(k_{1}, \bar{m}\right)$ and there is imperfect monitoring otherwise. Note that if $\bar{m} \geq K$, then there is never perfect monitoring for any $\underline{m}<K$, since then $m^{*}\left(k_{1}, \bar{m}\right)=K$. So, consider the case of $\bar{m}<K$ where $m^{*}\left(k_{1}, \bar{m}\right)=\frac{K\left(\bar{m}-k_{1}\right)}{K_{-1}}$. Substituting this into $\underline{m}>m^{*}\left(k_{1}, \bar{m}\right)$ and rearranging yields $\bar{m}<\underline{m}+k_{1}\left(\frac{K-\underline{m}}{K}\right) \equiv \underline{x}\left(k_{1}\right)$, where $\underline{x}\left(k_{1}\right) \in(\underline{m}, K)$ for any $\underline{m}<K$. Thus, it follows that monitoring can be perfect if $\bar{m}<\underline{x}\left(k_{1}\right)$, as this implies $\underline{m}>m^{*}\left(k_{1}, \bar{m}\right)$. Otherwise, there is imperfect monitoring.

Proof of Proposition 2. Given $k_{i} V^{c}$ in (7) is strictly decreasing in $T$, the optimal equilibrium profits for firm $i$ can be found by evaluating it at $T^{*}\left(k_{1}, k_{n}, p^{c}\right)$. Thus, it follows from (9) that:

$$
1-\delta^{T^{*}}=\frac{(1-\delta)(K-\widehat{m}) p^{c}}{\delta\left[\left(1-G\left(m^{*}\left(k_{1}, \bar{m}\right)\right)\right) K\left(p^{c}-\underline{p}\right)-(K-\widehat{m}) p^{c}\right]} .
$$

Then, substituting this into (7) yields:

$$
k_{i} V^{c}=\frac{k_{i}}{K}\left(\frac{\widehat{m}-G\left(m^{*}\left(k_{1}, \bar{m}\right)\right) K}{1-G\left(m^{*}\left(k_{1}, \bar{m}\right)\right)}\right) p^{c}, \forall i .
$$

This is strictly increasing in $p^{c}$, so $p^{c}=1$ and $k_{i} V^{*}$ is as claimed. Substituting $p^{c}=1$ into (10) and (11) yields:

$$
\delta \geq \frac{1}{1-G\left(m^{*}\left(k_{1}, \bar{m}\right)\right)} \frac{k_{n}}{K} \equiv \delta^{*}\left(k_{1}, k_{n}\right)
$$

and

$$
G\left(m^{*}\left(k_{1}, \bar{m}\right)\right)<\frac{K_{-n}}{K},
$$


respectively. Furthermore, note that $\delta^{*}\left(k_{1}, k_{n}, p^{c}\right)$ is strictly decreasing in $p^{c}$, such that collusion under trigger-sales strategies is not sustainable for any $\delta<\delta^{*}\left(k_{1}, k_{n}\right)$ for any $p^{c} \leq 1$. Finally, it follows from $\frac{\partial G\left(m^{*}\right)}{\partial \bar{m}}>0$ for all $\bar{m}<K$ that there is a unique level of $\bar{m}$, denoted $\bar{x}\left(k_{1}, k_{n}\right)$, that sets $G\left(m^{*}\left(k_{1}, \bar{m}\right)\right)=\frac{K_{-n}}{K}<1$, where $\bar{x}\left(k_{1}, k_{n}\right)<K$ and where $G\left(m^{*}\left(k_{1}, \bar{m}\right)\right) \in\left(0, \frac{K_{-n}}{K}\right)$ for all $\bar{m} \in\left[\underline{x}\left(k_{1}\right), \bar{x}\left(k_{1}, k_{n}\right)\right)$. This implies $\delta^{*}\left(k_{1}, k_{n}\right) \in\left(\frac{k_{n}}{K}, 1\right)$ and $k_{i} V^{*} \in\left(\pi_{i}^{N}\left(k_{n}\right), k_{i} \frac{\widehat{m}}{K}\right)$ for all $\bar{m} \in\left[\underline{x}\left(k_{1}\right), \bar{x}\left(k_{1}, k_{n}\right)\right)$.

Proof of Proposition 3. Differentiating $\delta^{*}\left(k_{1}, k_{n}\right)=\frac{1}{\left(1-G\left(m^{*}\left(k_{1}, \bar{m}\right)\right)\right)} \frac{k_{n}}{K}$ with respect to $k_{j}$ yields:

$$
\frac{\partial \delta^{*}}{\partial k_{j}}=\frac{1}{K\left[1-G\left(m^{*}\right)\right]}\left[\frac{\partial k_{n}}{\partial k_{j}}+k_{n} \frac{g\left(m^{*}\right)}{1-G\left(m^{*}\right)} \frac{\partial m^{*}}{\partial k_{1}} \frac{\partial k_{1}}{\partial k_{j}}\right] .
$$

Thus, $\frac{\partial \delta^{*}}{\partial k_{1}}<0$ from $\frac{\partial k_{n}}{\partial k_{1}} \in[-1,0], \frac{\partial m^{*}}{\partial k_{1}}<0$ for all $\bar{m}<K$ and $\frac{\partial k_{1}}{\partial k_{1}}=1$. Furthermore, $\frac{\partial \delta^{*}}{\partial k_{n}}>0$ from $\frac{\partial k_{n}}{\partial k_{n}}=1, \frac{\partial m^{*}}{\partial k_{1}}<0$ for all $\bar{m}<K$ and $\frac{\partial k_{1}}{\partial k_{n}} \in[-1,0]$. Finally, $\underline{\delta}^{*}\left(k_{n}\right)=\frac{k_{n}}{K}$ implies $\frac{\partial \delta^{*}}{\partial k_{n}}>0$.

Proof of Proposition 4. Differentiating $\widehat{p}^{c}\left(k_{1}, \bar{m}\right)=\frac{K}{\bar{m}} V^{*}$ with respect to $k_{j}$ yields:

$$
\frac{\partial \widehat{p}^{c}}{\partial k_{j}}=\frac{K}{\widehat{m}} \frac{\partial V^{*}}{\partial k_{j}}=-\frac{(K-\widehat{m}) g\left(m^{*}\right)}{\widehat{m}\left(1-G\left(m^{*}\right)\right)^{2}} \frac{\partial m^{*}}{\partial k_{1}} \frac{\partial k_{1}}{\partial k_{j}} .
$$

Thus, $\frac{\partial \widehat{p}^{c}}{\partial k_{1}}>0$ from $0<\widehat{m}<\bar{m}<K, \frac{\partial m^{*}}{\partial k_{1}}<0$ for all $\bar{m}<K$ and $\frac{\partial k_{1}}{\partial k_{1}}=1$.

Proof of Proposition 5. We first show that $\widehat{p}^{N}\left(k_{n}^{\prime}, \widehat{m}\right)>\widehat{p}^{c}\left(k_{1}, \bar{m}\right)$ if $\bar{m}>\bar{x}\left(k_{1}, k_{n}^{\prime}\right)$. This follows since $\widehat{p}^{N}\left(k_{n}^{\prime}, \widehat{m}\right)>\widehat{p}^{c}\left(k_{1}, \bar{m}\right)$ if $G\left(m^{*}\left(k_{1}, \bar{m}\right)\right)>1-\frac{k_{n}^{\prime}}{K}$. Furthermore, in Proposition $2, \bar{x}\left(k_{1}, k_{n}\right)$ is defined as the level of $\bar{m}$ that solves $G\left(m^{*}\left(k_{1}, \bar{x}\left(k_{1}, k_{n}\right)\right)\right)=1-\frac{k_{n}}{K}$. Thus, $\bar{x}\left(k_{1}, k_{n}^{\prime}\right)$ is the level that solves $G\left(m^{*}\left(k_{1}, \bar{x}\left(k_{1}, k_{n}^{\prime}\right)\right)\right)=1-\frac{k_{n}^{\prime}}{K}$ where $\bar{x}\left(k_{1}, k_{n}^{\prime}\right)>\underline{x}\left(k_{1}\right)$. This and $\frac{\partial G\left(m^{*}\right)}{\partial \bar{m}}>0$ implies that if $\bar{m}>\bar{x}\left(k_{1}, k_{n}^{\prime}\right)$, such that $G\left(m^{*}\left(k_{1}, \bar{x}\left(k_{1}, k_{n}\right)\right)\right)>1-\frac{k_{n}^{\prime}}{K}$, then $\widehat{p}^{N}\left(k_{n}^{\prime}, \widehat{m}\right)>\widehat{p}^{c}\left(k_{1}, \bar{m}\right)$.

Next, note that this comparison is only meaningful if $\bar{m}<\bar{x}\left(k_{1}, k_{n}\right)$ and if $\delta \geq \delta^{*}\left(k_{1}, k_{n}\right)$ such that $\widehat{p}^{c}\left(k_{1}, \bar{m}\right)$ is an equilibrium average price. So, we next show that $\bar{x}\left(k_{1}, k_{n}^{\prime}\right)<\bar{x}\left(k_{1}, k_{n}\right)$ if $k_{n}^{\prime}>k_{n}$ such that $k_{1}^{\prime} \leq k_{1}$. Using the implicit function theorem on $Z \equiv 1-\frac{k_{n}}{K}-G\left(m^{*}\left(k_{1}, \bar{m}\right)\right)=$ 0 yields:

$$
\frac{\partial \bar{x}}{\partial k_{j}}=-\frac{\frac{\partial Z}{\partial k_{j}}}{\frac{\partial Z}{\partial \bar{m}}}=-\frac{1}{\left(g\left(m^{*}\right) \frac{\partial m^{*}}{\partial \bar{m}}\right)}\left(\frac{1}{K} \frac{\partial k_{n}}{\partial k_{j}}+g\left(m^{*}\right) \frac{\partial m^{*}}{\partial k_{1}} \frac{\partial k_{1}}{\partial k_{j}}\right) .
$$

It follows from this that $\frac{\partial \bar{x}}{\partial k_{n}}<0$, since for all $\bar{m}<K, \frac{\partial m^{*}}{\partial \bar{m}}>0, \frac{\partial k_{n}}{\partial k_{n}}=1, \frac{\partial m^{*}}{\partial k_{1}}<0$ and $\frac{\partial k_{1}}{\partial k_{n}} \in[-1,0]$. So, if $k_{n}^{\prime}>k_{n}$, then $\bar{x}\left(k_{1}, k_{n}^{\prime}\right)<\bar{x}\left(k_{1}, k_{n}\right)$.

Thus, the above implies that, for any $\delta \geq \delta^{*}\left(k_{1}, k_{n}\right)$, if $k_{n}^{\prime}>k_{n}$ (so $k_{1}^{\prime} \leq k_{1}$ ), then there exists a unique $\bar{x}\left(k_{1}, k_{n}^{\prime}\right) \in\left(\underline{x}\left(k_{1}\right), \bar{x}\left(k_{1}, k_{n}\right)\right)$ such that if $\bar{x}\left(k_{1}, k_{n}^{\prime}\right)<\bar{m}<\bar{x}\left(k_{1}, k_{n}\right)$, then 
$\widehat{p}^{N}\left(k_{n}^{\prime}\right)>\widehat{p}^{c}\left(k_{1}, \bar{m}\right)$. Finally, notice that if $\bar{x}\left(k_{1}, k_{n}^{\prime}\right)<\bar{m}<\bar{x}\left(k_{1}, k_{n}\right)$, then $\bar{x}\left(k_{1}^{\prime}, k_{n}^{\prime}\right)<\bar{m}$ from $k_{1}^{\prime} \leq k_{1}$ and $\frac{\partial \bar{x}}{\partial k_{1}}>0$. Consequently, it follows from Proposition 2 that collusion under trigger-sales strategies is not sustainable for $\left(k_{1}^{\prime}, k_{n}^{\prime}\right)$. 